\section{Renomegaly Associated with a Mycobacterial Infection in Summer Flounder Paralichthys dentatus}

\author{
Kathleen P. Hughes, Robert B. Duncan, Jr. \\ and Stephen A. Smith* \\ Aquatic Medicine Laboratory, Department of Biomedical \\ Sciences and Pathobiology, Virginia-Maryland Regional \\ College of Veterinary Medicine, Virginia Polytechnic \\ Institute and State University, Blacksburg, \\ VA 24061 USA
}

(Received October 8, 2001)

\begin{abstract}
A population of juvenile $(28 \mathrm{~cm}, 180 \mathrm{~g})$ summer flounder Paralichthys dentatus developed severe coelomic distention, anorexia and lethargy over a period of 4 to 6 months. Gross internal lesions included a large coelomic mass that replaced the posterior kidney and yellow foci on the heart, spleen and liver. Histopathologically, the posterior kidney was obliterated by extensive granulomatous inflammation and rare calcified granulomas. Special stains revealed extracellular acid-fast bacilli in the areas of inflammation. An isolated bacterium belonging to the genus Mycobacterium was the presumptive causative agent of these lesions.
\end{abstract}

Key Words: Paralichthys dentatus, renomegaly, mycobacteriosis, granulomatous inflammation, summer flounder

The mariculture of summer flounder, Paralichthys dentatus, is becoming increasingly popular in the United States due to the demand for this fish in both recreational and commercial fish markets. Wild stocks of flounder species in North America have significantly declined over the past 20 years because of increasing numbers of flounder fishermen and the introduction of more efficient harvesting techniques. ${ }^{1,2)}$ The worldwide commercialization of flatfish aquaculture is of primary importance because of high consumer demand and favorable market prices. As with intensive culture of other fish species, the summer flounder is susceptible to a multitude of viral, bacterial and parasitic infections. ${ }^{3-5)}$ However, since the practice of flounder aquaculture is relatively new in this country, there are few documented reports of specific diseases in cultured flounder species.

\footnotetext{
* Corresponding author

E-mail: stsmith7@vt.edu
}

One of the principle bacterial pathogens associated with cultured fish is Mycobacterium spp. Infections of this acid-fast bacteria have been reported in numerous marine fish species, including striped bass, sea bass, and plaice. ${ }^{6-10)}$ Mycobacteriosis is an important disease not only because of the production loss in affected populations but also because of its zoonotic potential. Mycobacteriosis in fish is a slow-developing chronic disease that may or may not manifest overt external signs. ${ }^{5)}$ External clinical signs of infection may include lethargy, anorexia and skin ulcerations. Internally, organs such as the kidney, spleen or liver may have granulomatous inflammation and caseous necrosis. ${ }^{5)}$ Mycobacterium sp. may be horizontally and vertically transmitted in an infected fish population. ${ }^{11)}$ Currently, there is no effective treatment, thus elimination of the infected stock is recommended.

\section{Disease Occurrence}

A population of two hundred and fifty commerciallyreared juvenile $(28 \mathrm{~cm}, 180 \mathrm{~g})$ summer flounder were held at the Aquatic Medicine Laboratory of the VirginiaMaryland Regional College of Veterinary Medicine for over a year in a recirculating saltwater system with a fine sand substrate. Water quality parameters were routinely monitored. Parameters measured were water temperature $\left(18-20^{\circ} \mathrm{C}\right)$, ammonia $(<0.02 \mathrm{ppm}), \mathrm{pH}(7.8-$ 8.0 ), and salinity (16-20 ppt). Salinities were adjusted using a synthetic sea salt (Forty Fathoms Crystal Sea Salt, Marine Enterprises International, Inc., Baltimore, $M D$ ). Fish were fed a pelleted commercial sinking feed (Zeigler Brothers, Inc., Gardners, PA; $6.4 \mathrm{~mm}, 38 \%$ protein) once a day to satiation. Historically, the fish had been exposed to different experimental salinity manipulations (0 ppt, $15 \mathrm{ppt}$ and $32 \mathrm{ppt}$ ), but were not intentionally exposed to any pathogens. Fish had been also periodically treated with formalin in a bath exposure $(20$ $\mathrm{ppm}$ ) to reduce a chronic external parasite infestation of Trichodina sp. Over a four to six month period, approximately thirty fish in the population $(12 \%)$ developed severe coelomic distention. The fish gradually became anorexic and lethargic. No other external clinical signs were noted.

\section{Disease signs}

Prior to euthanasia, coeliocentesis and gastric lavages were performed, but results were inconclusive. All clinically affected fish were humanly euthanitized via tricaine methanesulfonate $(100 \mathrm{mg} / \mathrm{L}$, MS-222, Sigma Chemical Co., St. Louis, MO) overdose and necropsies were performed. Gross examination revealed large redtan colored multilobulated masses in the region of the posterior kidney (Figs. 1 and 2). Tissue representative of normal posterior kidney could not be identified in these fish. Several small, $1 \mathrm{~mm}$ diameter, yellow foci were noted on the liver, spleen and heart. There was a moder- 


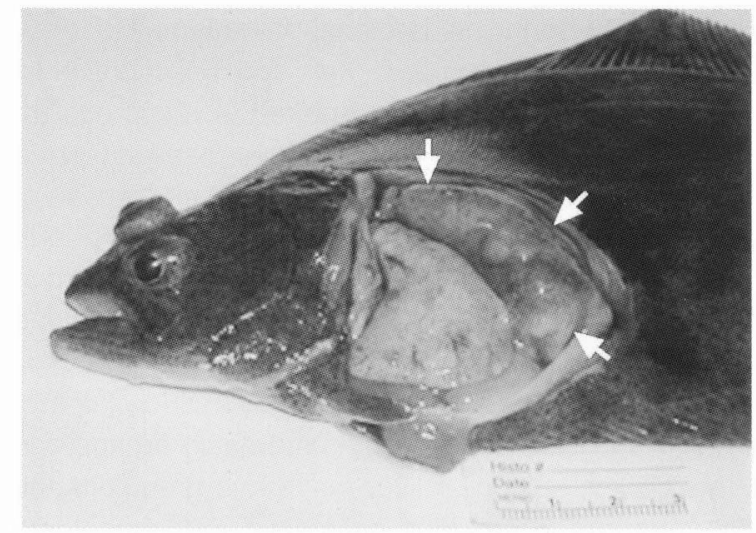

Fig. 1. Summer flounder with coelom exposed. Arrows indicate large mass in coelomic cavity in region where posterior kidney is typically found.

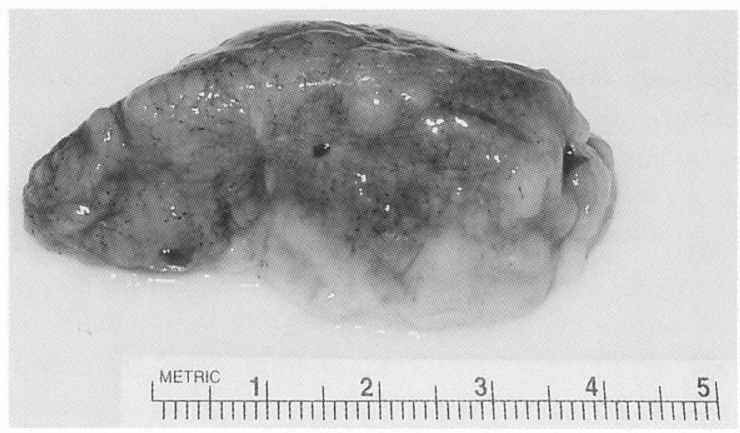

Fig. 2. Mass excised from coelom of summer flounder in Figure 1. Posterior renal tissue is usually dark in color. Melanomacrophage centers are noted on the surface of this mass.

ate amount of turbid pale yellow fluid in the coelom, characterized as a transudate because of its low protein and cellularity. Impression smears were made of the coelomic masses and stained with a modified Wright's and Ziehl-Neelsen stains. Impression smears of renal tissue revealed numerous foamy macrophages and hematopoietic cell precursors (Fig. 3 ).

\section{Histopathology}

Tissue samples of the gill, heart, liver, spleen, gastrointestinal tract and coelomic mass were collected and fixed in $10 \%$ neutral buffered formalin for routine histologic examination. Tissues were embedded in paraffin, sectioned at $5 \mu \mathrm{m}$, and stained with hematoxylin and eosin. Given the clinical presentation, additional special stains of Brown-Hopps, Ziehl-Neelsen and Steiner's were also applied to tissue sections.

Histologically, the coelomic lesions in the affected fish were identified as posterior kidney with marked effacing and coalescing nodular granulomatous inflammation primarily composed of epithelioid macrophages (Fig. 4). There were rare mineralized granulomas delimited by fibrous capsules with central calcification. The number of melanomacrophage centers was consid-

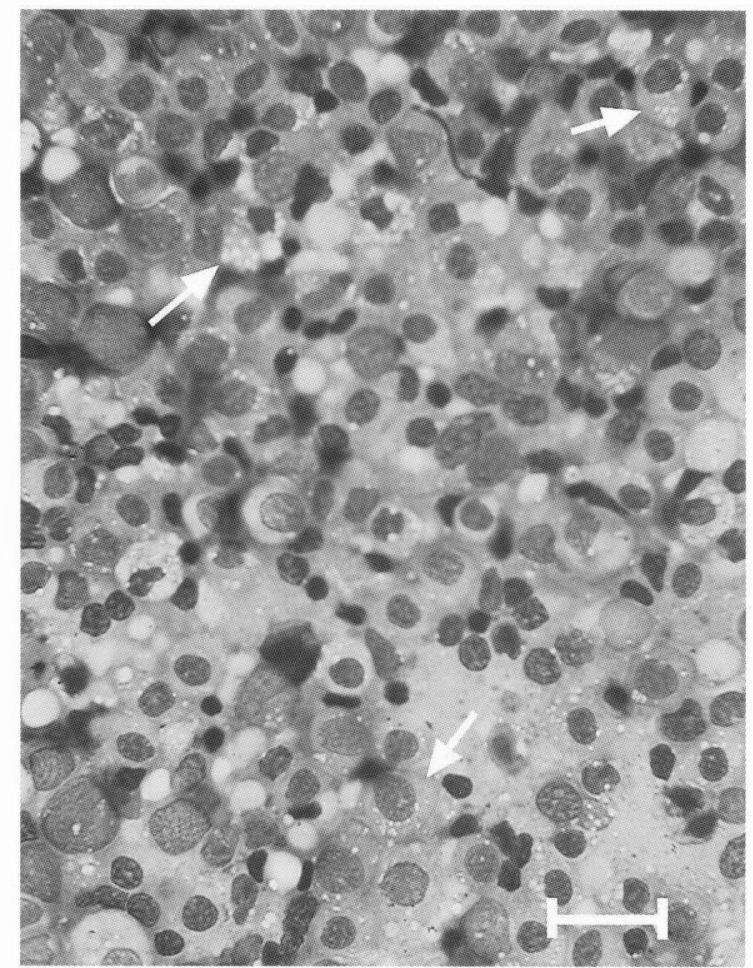

Fig. 3. Impression smear of coelomic mass stained with a modified Wright's stain. (magnification: 1000x). Numerous macrophages and few hematopoietic precursors are present. Arrows indicates a tissue macrophage with cytoplasmic vacuoles.

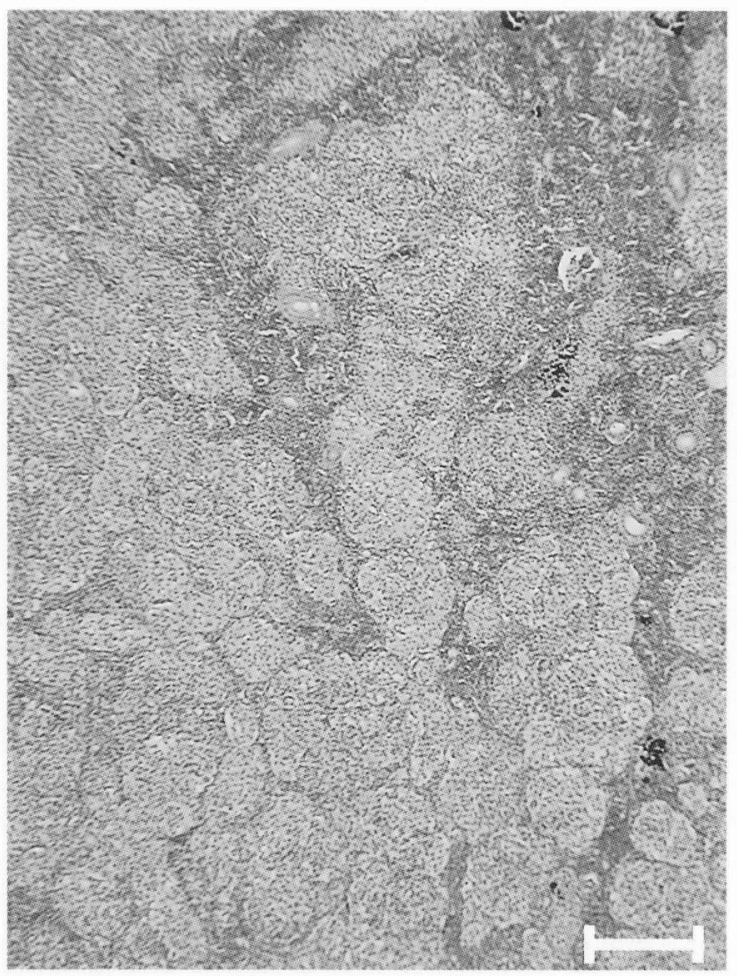

Fig. 4. Posterior kidney stained with H\&E (magnification: 100x). Coalescing granulomatous inflammation obliterates most of the pre-existing parencyma. 


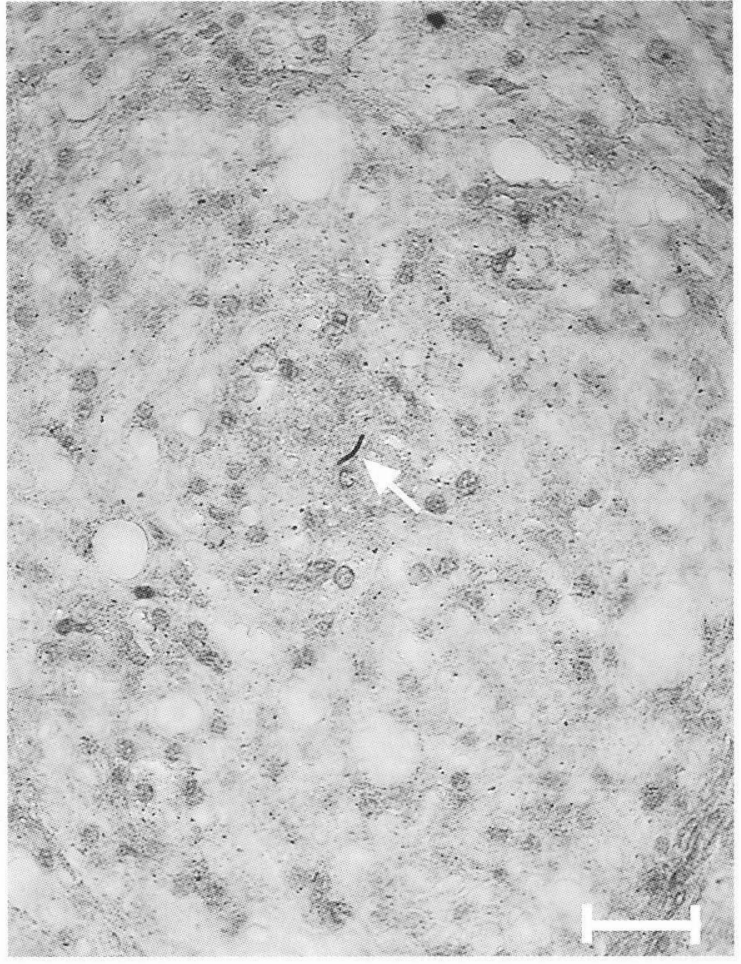

Fig. 5. Posterior kidney (magnification: 1000x) stained with Steiner's. Stained bacteria (arrow) in the area of granulomatous inflammation.

ered to be within normal limits for this species. The heart, stomach, intestine and mesentery of these fish also had multifocal granulomatous inflammation similar to that observed in the kidney. Special stains revealed Gram positive, acid-fast bacilli within areas of inflammation (Fig. 5).

\section{Bacterial Isolation}

Bacterial cultures were taken from the liver and coelomic mass of 20 clinically diseased fish. Samples were cultured on $2 \% \mathrm{NaCl}$ trypticase soy agar (TSA, Becton Dickinson Systems, Cockeysville, MD) and then transferred to Middlebrook and Lowenstein-Jensen agar (Remel, Lenexa, KS) and incubated at $25^{\circ} \mathrm{C}$. Small raised yellow bacterial colonies grew within 10-15 days on the $2 \% \mathrm{NaCl}$ TSA agar. Subcultures on the Middlebrook and Lowenstein-Jensen media grew small acid-fast bacilli presumptively identified as belonging to the genus Mycobacterium. Gas chromatography techniques confirmed the identification as a mycobacterial species and initial gene sequencing of the isolate demonstrated the bacteria to have close homology with $M$. marinum and $M$. ulcerans. ${ }^{6)}$

\section{Etiology}

The extensive renal lesions described in this case represent an unusual response to Mycobacterium sp. infection. The typical teleost response to a mycobacterial infection is formation of multiple discrete granulomas or tubercles with large numbers of intracellular bacteria. ${ }^{8,12)}$ In chronic bacterial infections, such as with Mycobacterium sp., fish may initially respond with granulomatous inflammation consisting of macrophages, epithelioid cells, lymphocytes, plasma cells and fibroblasts. This granulomatous inflammation may be so extensive it obliterates the involved tissue. ${ }^{13)}$ Over time this granulomatous inflammation organizes into discrete granulomas which may or may not mineralize. Similar reports describe a similar intense infiltration of epithelioid macrophages in sea bass (Dicentrarchus labrax) as a pregranulomatous response (4-6 weeks post-inoculation), which displaces normal tissue, however, it eventually forms multifocal granulomata. ${ }^{8)}$ A few granulomas were observed, but the overwhelming tissue response in these summer flounder, was a less organized and effacing granulomatous inflammation with low numbers of extracellular bacteria within areas of inflammation. The summer flounder in this case exhibited coelomic distention, an external clinical sign of infection, for at least four months prior to euthanasia. The marked, disseminated granulomatous inflammation with minimal organization and the presence of acid-fast bacteria represents an exuberant and atypical response when compared to previous reports of mycobacterial infections in other fish species.

\section{Acknowledgments}

The authors would like to thank Ms. Dawn Jones and Dr. Thomas Inzana of the Bacteriology Laboratory at the Virginia-Maryland Regional College of Veterinary Medicine for their assistance in identifying the bacterial agent isolated in this case. Thanks are also owed to Dr. Jeffrey Wolf for his assistance with characterizing the histopathology in this case.

\section{References}

1) Waters, E. B. (1996): Sustainable flounder culture and fisheries. The Task Force on Flounder Culture and Stock Enhancement. Sea Grant Publication, Raleigh, N. C. 2) Nash, C. E. and A. J. Novotny (1995): Production of Aquatic Animals. World Animal Science C8, Elsevier Science B. V., The Netherlands. pp. 329338. 3) Austin, B. (1999): Bull. Eur. Ass. Fish Pathol., 19, 231-234. 4) Frerichs, G. N. (1989): Vet. Rec., 125 , 315-318. 5) Fryer, J. L. and J. S. Rohovec (1984): Helgolander Meeresunters, 37, 533-545. 6) Heckert, R. A., S. Elankumaran, A. Milani and A. Baya (2001): J. Clinical Microbiol., 39, 710-715. 7) Wolf, J. C. and S. A. Smith (1999): Dis. Aquat. Org., 38, 191-200. 8) Colorni, A., R. Avtalion, W. Knibb, E. Berger, B. Colorni and B. Timan (1998): Aquaculture, 160, 1-17. 9) Hedrick, R. P., T. McDowell and J. Groff (1987): J. Wildlife Dis., 23, 391-395. 10) Timur, G., R. J. Roberts and 
A. McQueen (1977): J. Comp. Pathol., 87, 83-87. 11) Stoskopf,. M. F. (1992): Fish Medicine, W. B. Saunders Co., Philadelphia, PA, pp. 560.12$)$ Bruno, D. W., J. Griffiths, C. G. Mitchell, B. P. Wood, Z. J. Fletcher, F. A. Drobniewski and T. S. Hastings (1998): Dis. Aquat. Org.,
33, 101-109. 13) Ferguson, H. W (1989): Systemic Pathology of Fish, text and atlas of comparative tissue responses in diseases of teleosts. lowa State University Press, Ames, lowa, pp. 6. 